\title{
LA ESPADA DE LA CATEDRAL DE BARCELONA
}

\author{
por \\ Juan-Eduardo Cirlot
}

EN Barcelona se conserva una de las espadas más bellas del mundo (Figs. 1 a-b). Nos atrevemos a decirlo después de haber visto la llamada "de Carlomagno" del Louvre, las de la Armería Real de Madrid, las del Lázaro Galdiano en la misma capital, las de los Museos de París, Ginebra, Zurich, Nuremberg, Turín, Milán y Venecia, aparte del conocimiento documental de las que se conservan en otros lugares. La espada de Barcelona se encuentra en el tesoro de la catedral, no en el pequeño museo con acceso por el claustro, sino entre las esplendorosas custodias y báculos, junto a los cálices, códices y arquillas, al lado de la espléndida silla gótica de plata dorada del rey Martín y de la tan restaurada corona del mismo monarca. Tal vez por su situación adquiere o, mejor, ratifica, el valor místico que la reina de las armas posee siempre y que se acrecienta con el paso del tiempo, con la metamorfosis de la sociedad y de la guerra. En efecto, ahora no es posible, casi, ver la espada como un arma física; es más bien un arma espiritual, un símbolo de poder y de capacidad en esa "agresividad superior" que identificamos con el espíritu. La belleza de la espada de Barcelona reside en la originalidad de su forma, tanto en la guarda de hierro cincelado como en la hoja, en el matiz dorado viejo que la recubre por entero, en sus proporciones admirables y en las calidades de su materia. No tiene ni esa textura atormentada que suelen poseer las armas de excavación, ni tampoco la lisura "de nuevo" de las piezas privilegiadas de ciertas colecciones, como, por ejemplo, de los estoques de la Real Armería madrileña. Si bien es cierto que no posee la alta época de la espada románica del Louvre, a que aludíamos al principio de este texto, ni siquiera la de la espada atribuida a Fernando III de la Real Armería, corresponde, en cambio, a un momento interesantísimo, a ese ocaso de la Edad Media tan bien analizado por Huizinga en su famoso libro, y cuyo perfume percibimos en la pintura de Huguet (Figs. 2-3). La última floración del gótico se halla, pues, perfectamente representada en esta espada barcelonesa cuya pureza estilística es otra de sus relevantes cualidades.

Pero su interés se ve acrecentado por el hecho de que es una pieza histórica, no perdida en el anónimo total que envuelve a tantas armas importantes, ni adobada con los falsos prestigios de una atribución absurda cuando no ridícula, como las que esmaltaban los catálogos de ciertas armerías a fines del pasado siglo, y aún inspiran que, en 
determinadas exposiciones, se exhiban, como espada del Cid, armas con empuñadura de la segunda mitad del siglo xv, sin ninguna advertencia sobre el hecho en artículos de prensa. Esta espada de la catedral de Barcelona perteneció a Pedro, condestable de Portugal, que reinó efímeramente en Cataluña, como resultado de sus propios problemas y aventurosa existencia, y como resultado también de la contienda de los catalanes con Juan II de Aragón. Pedro (1429-1466) es un personaje nobilísimo, aureolado por un romanticismo lejano, que le presta su vida azarosa, de la que daremos un breve resumen. Hijo del infante don Pedro, duque de Coimbra, a los quince años era nombrado cronista de Alfonso $\mathrm{V}$, rey de Portugal. Poco después le armaba caballero el infante don Enrique, en el Monasterio de San Jorge, de Coimbra; a los dieciséis años combatía en Castilla en favor de Alvaro de Luna contra los infantes de Aragón. Al morir su tío el infante don Juan, fue nombrado condestable. Desde su juventud sintió la misma atracción por las armas que por las letras. Se sabe que, en 1449, a los veinte años, obtenía del marqués de Santillana-con quien habia trabado amistad-que le enviara, por medio de Alvar González de Alcántara, sus obras poéticas. Su destino político, que hubiera podido ser brillante en su patria, se truncó con la batalla de Alfarrobeira, en la que murió su padre. Disensiones de éste con el monarca motivaron que se le despojara de sus bienes y se le castigara con el destierro. Pero se dirigió a Castilla, donde vivió nueve años, hasta 1457, de un modo "mísero y errante". En esa época se formaría su peculiar sentimentalismo poético, que refleja su divisa "Paine pour joie" (Dolor por alegría), que se ha interpretado de maneras diversas, tal como lo recoge Martínez Ferrando (1), pareciendo la más lógica la que asimila el concepto al "Durch Leiden Freude" beethoveniano ( $A$ la alegría por el dolor).

Un caballero de sangre real se vio obligado, pues, a vivir como noble sin peculio, ayudado por amistades y recursos diversos. En ese período de su existencia cultivó la literatura y aprendió el castellano, escribiendo su Satyra de felice $e$ infelice vida, obra inspirada en el Laberinto, de Mena, pero dotada de un inconfundible carácter, que pudiéramos llamar "decadente" y que se relaciona más con la saudade portuguesa que con el conceptismo, aunque lo utilice, así como las hipérboles y alegorías que eran del gusto de la época, siguiendo la tónica del célebre Roman de la Rose. Más tarde, Pedro escribió la Tragedia de la insigne Reyna doña Isabel, en forma dialogada y dedicada a la memoria de su hermana. En 1457, Alfonso $V$ le levanta el

(1) J.-Ennest Martinez Ferrando: Père de Portugal, "Rei dels Catalans". Barcelona, 1936. 
destierro. Pedro retorna a su patria, donde sin duda no vio colmadas sus ambiciones. En 1465, habiendo muerto el príncipe de Viana, los catalanes, que han roto su juramento de fidelidad a Juan II, ofrecen la corona a Enrique IV de Castilla, que rehúsa. Piensan luego en el condestable de Portugal, en Pedro, por ser éste nieto del conde de Urgel, Jaime el Desdichado. En 1465 mandan una embajada y Pedro acepta la corona, que le obliga a una guerra con el monarca aragonés, llegando a Barcelona por mar. Jura los privilegios del reino. Derrota en febrero de ese año al conde de Prades, toma la Bisbal. Pero la vida de campaña quebranta su salud, nada vigorosa. Hay muchos documentos sobre el efímero reinado catalán de Pedro, que acuñó monedas y al que FIuguet pinta, al parecer, dos veces: una (Fig. 2), en el retablo de San Bernardino de Siena y del Santo Angel custodio (catedral de Barcelona), y otra (Fig. 3), como uno de los reyes magos, en la tabla de la Epifanía, del retablo llamado "del Condestable» (capilla de Santa Agueda, Barcelona). Pedro, al que testimonios de la época, juzgan bello y apuesto, aparece en estos retratos más bien como retraido y lejano. Los documentos hablan de su gusto por el arte y lo refinado y suntuoso. No es de extrañar se hiciera labrar una espada como la que ahora perpetúa su recuerdo y que se sabe suya por la divisa "Paine pour joie" que está grabada en la hoja, divisa que el rey hizo esculpir en marcos de ventana y que aparece también en el retablo de la capilla de Santa Agueda. Esta espada podría ser obra de un armero italiano, pues en los documentos antes aludidos aparece citado "el daguer Joan lo florentí", que también trabajó para el príncipe de Viana, por lo que se trataría de un artifice establecido ya en Barcelona antes de la llegada de Pedro. Hay el dato curioso de que el citado daguero cobró el precio de forjar "una espada, dos puñales y algunos cuchillos» para el monarca con la cesión de un esclavo negro (2). El rey amaba la orfebrería, tenía un hermoso tesoro de obras en oro y plata, que hizo fundir para socorrer a la ciudad de Tortosa. Pero la enfermedad le minaba y sucumbió a la tisis en 29 de junio de 1466, hallándose en el palacio de Juan de Montbuy, de Granollers. Murió, pues, en el día de su santo patrón San Pedro, signo de favor del cielo.

La espada del condestable-rey, que llegó a la catedral de Barcelona posiblemente poco después de la muerte del monarca, acaso como legado, pero de lo cual no tenemos noticia, es una espada de dos manos, muy semejante por las medidas-y por nada más-al mandoble de los Reyes Católicos de la Armería Real, pues éste mide 133 centímetros y la espada de Barcelona 132,5 centímetros. Como dijimos, está

(2) Op. cit. 
dorada en su totalidad por el peligroso procedimiento del dorado al fuego, que hoy no se practica y que es el único que admite el hierro directamente. La empuñadura está labrada con primoroso trabajo de tipo floral, muy intenso y estilizado. $\mathrm{El}$ pomo en forma de pera tiene un arrollamiento helicoidal que armoniza con el de paso mucho más fino de los brazos del arriaz. Estos brazos se curvan hacia arriba, en lugar de hacerlo hacia abajo, que es la estructura más normal y corriente. No se trata de una colocación al revés, debida a un montaje equivocado, pues el escudete de la parte central de la guarda está perfectamente colocado con el vértice sobre el recazo. Hay dibujos de miniaturas medievales y grabados de Durero con arriaces invertidos así, pero la falta de detalle impide ver si es disposición original o colocación equivocada al montar las piezas de la empunadura. También aparece el arriaz de curvatura invertida en obras de pintores prerrafaelistas. Esta disposición, en la pieza que comentamos, aumenta su esbeltez y le quita, acaso, algo del sentido directamente utilitario. ¿Fue arma de parada o de combate? Creemos que ambas cosas.

Las dimensiones de la espada son las siguientes: Longitud total, del pomo a la punta: 132,5 centímetros; id. empuñadura: 31,5 centimetros; longitud total de la hoja: 101 centímetros, que se subdivide del modo siguiente: recazo: cuatro centímetros; parte alta, de cuatro mesas (en realidad, dos con dos anchas canales que las dividen): 30,5 centímetros; parte media, de tres mesas (una, con una ancha canal en medio, donde está grabada la divisa; esa zona de en medio tiene una sección ligeramente cóncava en cada cara): 53,5 centímetros; parte baja, de dos mesas: 13 centímetros. Anchura máxima de la hoja: cuatro centímetros y medio.

Contemplada la espada del condestable-rey y los retratos del monarca, en la misma catedral (museo) y capilla de Santa Agueda, tan cercana, se puede terminar el periplo de homenaje a este príncipe - menos desventurado por su muerte prematura y por su, al fin y al cabo, derrota por Juan II, que por el hecho de que los historiadores de la literatura, despiadadamente, juzguen sus obras como "de aficionadon-visitando su sepulcro, que sigue ya para siempre siendo provisional, en el coro de la iglesia de Santa María del Mar, de Barcelona. Es una sencilla lauda en bajo relieve, ya medio borrado, en el que se vislumbra la cabeza del rey, el cuerpo y sus manos sosteniendo un libro. El magno sepulcro escultórico, con yacente revestida de armadura, que debió haber labrado Claperós, no llegó a hacersc. 

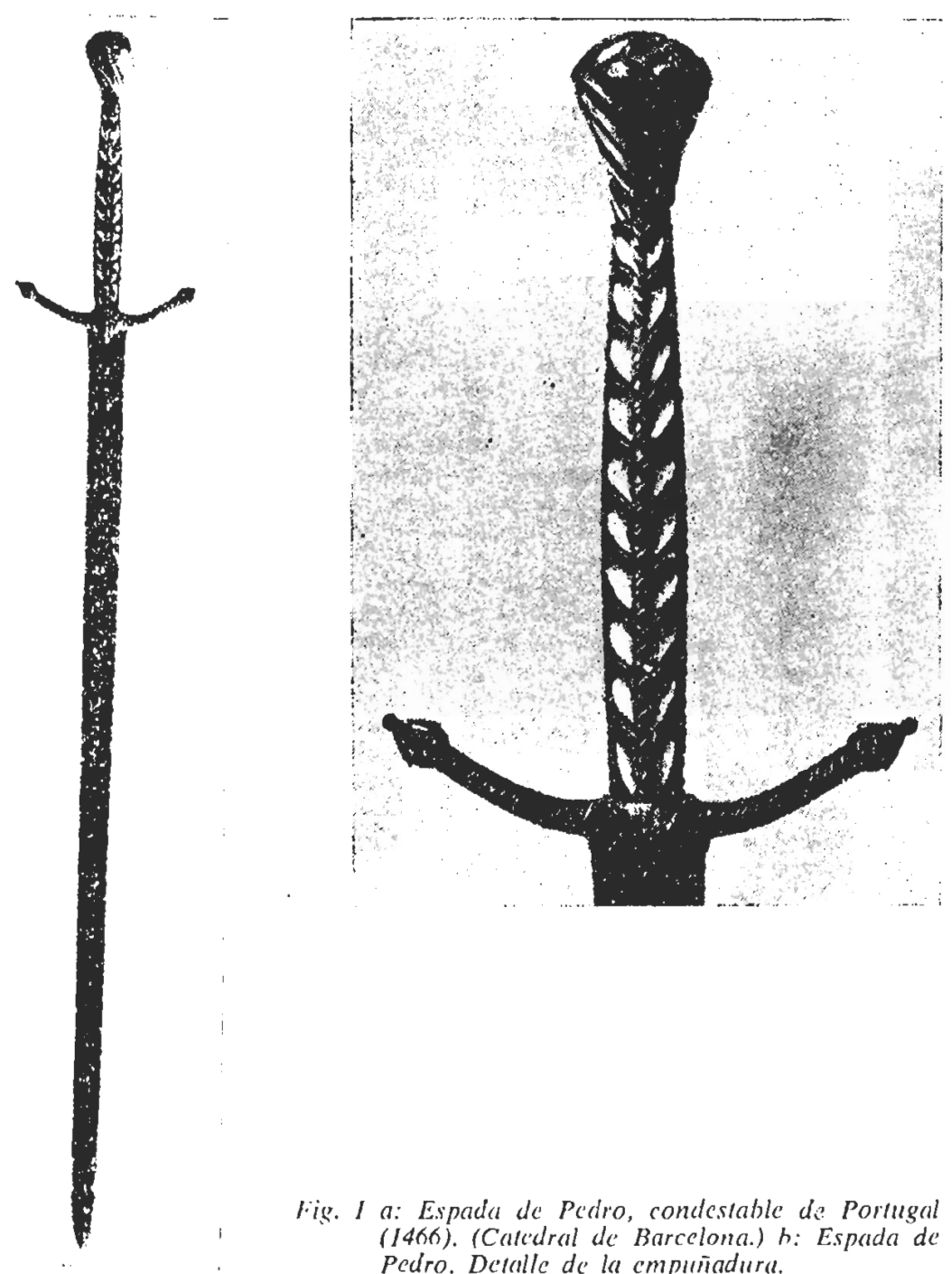

Fig. I a: Expada de Pedro, condestable de Porfugal (1466). (Catedral de Barcelona.) h: Espada de Pedro. Detalle de la cmpiñadura. 


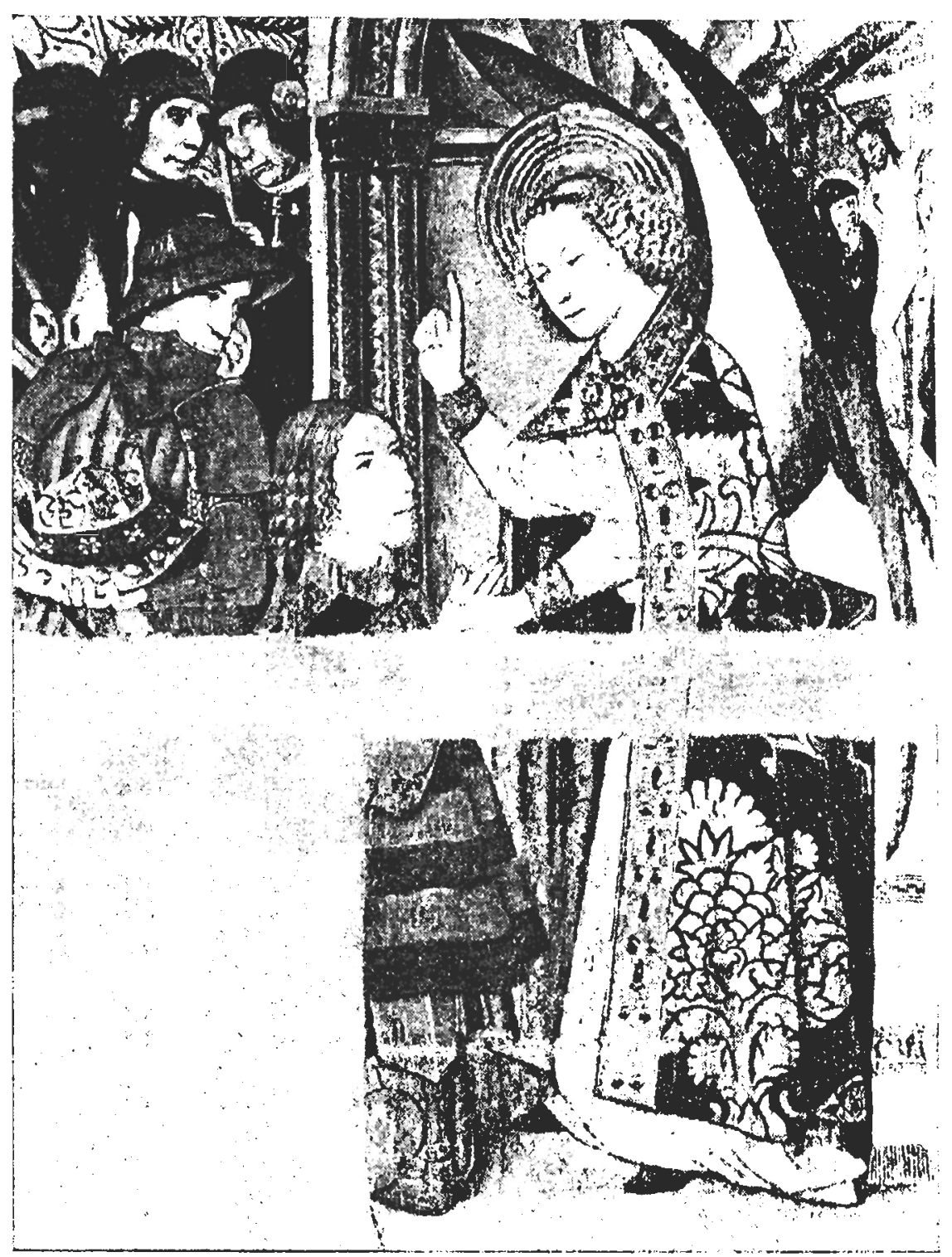

Fig. 2. Retrato que se supone de Pedro. condestable de Pormgal. (Refablo de San Bernardino, por Jaime Hugutl. 1466; (alcalral de Burcelona.) 


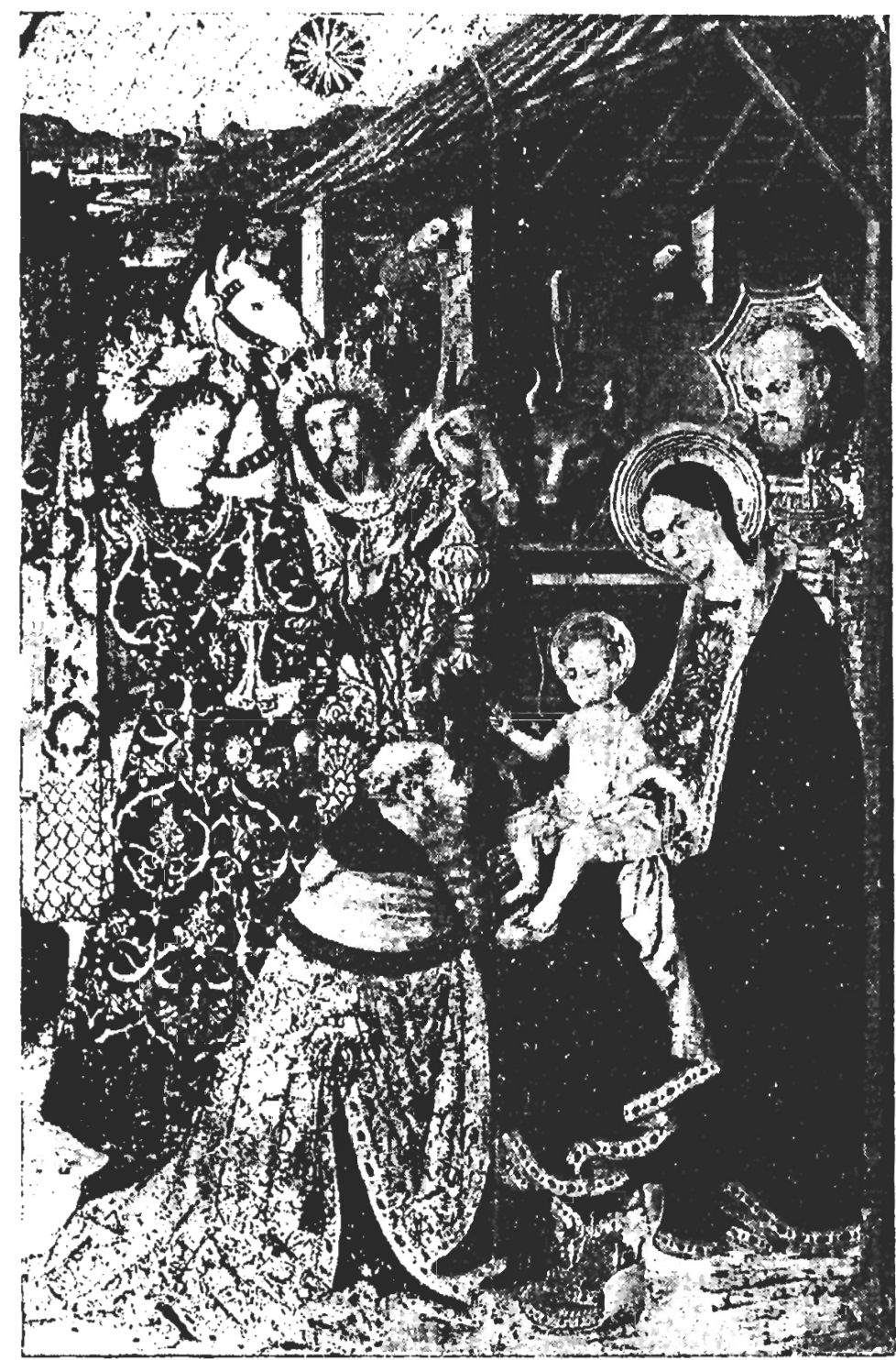

Fig. 3. Relralo supuesto de Pedro de Porlugal. figura de la izquierda, por Huguet. Relablo del condesiable. (Capilla de Sanla Agueda. Barcclona.) 